\title{
Elucidating the expression and function of Numbl during cell adhesion-mediated drug resistance (CAM-DR) in multiple myeloma (MM)
}

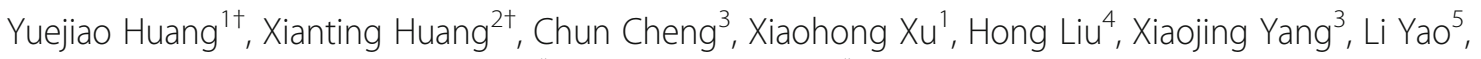
Zongmei Ding ${ }^{3}$, Jie Tang ${ }^{3}$, Song $\mathrm{He}^{6^{*}}$ and Yuchan Wang ${ }^{3^{*}}$

\begin{abstract}
Background: Cell adhesion-mediated drug resistance (CAM-DR) is a major clinical problem that prevents successful treatment of multiple myeloma (MM). In particular, the expression levels of integrin $\beta 1$ and its sub-cellular distribution (internalization and trafficking) are strongly associated with CAM-DR development.

Methods: Development of an adhesion model of established MM cell lines and detection of Numbl and Integrin $\beta 1$ expression by Western Blot analysis. The interaction between Numbl and Integrin $\beta 1$ was assessed by a coimmunoprecipitation (CO-IP) method. Calcein AM assay was performed to investigate the levels of cell adhesion. Finally, the extent of CAM-DR in myeloma cells was measured using cell viability assay and flow cytometry analysis.

Results: Our preliminary date suggest that Numbl is differentially expressed in a cell adhesion model of MM cell lines. In addition to binding to the phosphotyrosine-binding (PTB) domain, the carboxyl terminal of Numbl can also interact with integrin $\beta 1$ to regulate the cell cycle by activating the pro-survival PI3K/AKT signaling pathway. This study intends to verify and elucidate the interaction between Numbl and integrin $\beta 1$ and its functional outcome on CAM-DR. We have designed and developed a CAM-DR model using MM cells coated with either fibronectin or bone marrow stromal cells. We assessed whether Numbl influences cell-cycle progression and whether it, in turn, contributes to activation of PI3K/AKT signal pathway through the adjustment of its carboxyl end. Finally, we showed that the interaction of Numbl with integrin $\beta 1$ promotes the formation of CAM-DR in MM cells.
\end{abstract}

Conclusions: Our findings elucidated the specific molecular mechanisms of CAM-DR induction and confirmed that Numbl is crucial for the development of CAM-DR in MM cells.

Keywords: MM, Numbl, Integrin $\beta 1$, CAM-DR

\section{Background}

Multiple myeloma (MM), also named as plasma cell myeloma, is a relatively indolent yet therapeutically challenging neoplasm, with a median survival period of 3 to 5 years [1]. Currently, treatment options are limited and include chemical drugs and biological target therapy. Given the high

\footnotetext{
* Correspondence: hesong2009@126.com; ychan.wang@163.com

${ }^{\dagger}$ Yuejiao Huang and Xianting Huang contributed equally to this work.

${ }^{6}$ Department of Pathology, Nantong University Cancer Hospital, Nantong, Jiangsu 226001, People's Republic of China

${ }^{3}$ Department of Pathogenic Biology, School of Medicine, Nantong University, Nantong, Jiangsu 226001, People's Republic of China

Full list of author information is available at the end of the article
}

relapse rate and increased risk for drug resistance, there is a pressing need to identify potential therapeutic targets [2]. More specifically, the drug resistant nature of $M M$ is the major obstacle for the inefficacy of chemotherapy. Previous studies have shown that the bone marrow microenvironment is the main factor influencing the resistance of MM cells [3]. This microenvironment-mediated resistance (EMDR) consists of soluble factor-mediated drug resistance (SFM-DR) and cell adhesion-mediated drug resistance (CAM-DR), mainly involved in mediating the initial drug resistance. The initial drug resistance confers survival advantage to MM cells after preliminary drug exposure, leading to

(c) The Author(s). 2019 Open Access This article is distributed under the terms of the Creative Commons Attribution 4.0 International License (http://creativecommons.org/licenses/by/4.0/), which permits unrestricted use, distribution, and reproduction in any medium, provided you give appropriate credit to the original author(s) and the source, provide a link to the Creative Commons license, and indicate if changes were made. The Creative Commons Public Domain Dedication waiver (http://creativecommons.org/publicdomain/zero/1.0/) applies to the data made available in this article, unless otherwise stated. 
the formation of acquired drug resistance. Research suggests that CAM-DR is one of the major factors contributing to the development of drug resistance. A number of published studies confirm that MM cell adherence to stromal cells leads to most of the drug resistant phenotypes, and that disruption of signals mediating cell adhesion could significantly increase the sensitivity of tumor cells to chemotherapy drugs [4-6].

Studies have shown that members of the Integrin family of adhesion proteins are intimately involved in the mechanism of CAM-DR generation $[2,7,8]$. The signal cascade and cytoskeletal rearrangements induced by integrins are important etiological underpinnings of CAM-DR. Integrins are transmembrane glycoproteins made up of heterologous dimers and are localized at the cell surface. The integrins induce cell proliferation, retraction and migration. They also act as a adhesion receptors to link matrix proteins in between cells and facilitate the interaction between cells and the extracellular matrix (ECM). Integrins consist of 18 alpha subunits and $8 \beta$ subunits in total. These subunits form a total of 24 canonical integrins in different cell types [9]. Integrin $\beta 1$ is one of the integrins that is widely distributed and has been studied extensively. The current consensus is that integrin $\beta 1$ can combine with at least 12 different types of alpha subunits to coordinate the processes of cell adhesion and migration. Numerous studies have noted the high expression levels of integrin $\beta 1$ in a variety of invasive cancers. Berry M,G [10], and other investigators have reported high expression of integrin $\beta 1$ in highly invasive cancer cells isolated from breast cancer patients with low survival rates. This correlation suggested that the high expression of integrin $\beta 1$ could be a robust candidate as biomarker for breast cancer. Moreover, curtailment of integrin $\beta 1$ function by monoclonal antibodies has been shown to inhibit the invasiveness of breast cancer cells by approximately 80\% [10]. Integrin $\beta 1$ has also been reported to be highly expressed in patients with other malignancies, including gastric cancers, small cell lung cancers, and other tumors, suggestive of poor prognosis for patients $[11,12]$. Recent studies have highlighted that integrin $\beta 1$ mediated adhesion between cancer cells and the ECM can reduce the tumor cell cytotoxicity that is induced by radiotherapy and chemotherapy $[13,14]$. Consistently, Naci D [15] and others have found that integrin $\beta 1$ mediated adhesion between leukemic cells and the ECM can significantly inhibit the apoptosis induced by chemotherapy drugs. Further lending support to these findings, there is evidence to suggest that adhesion between mantle cell lymphoma (MCL) cells and the ECM is caused, in part, by abnormally elevated expression levels of integrin $\beta 1$, an important factor of tumor cell resistance to therapy [16].

Integrin $\beta 1$ is one of the major cell surface receptors mediating cell-cell and cell-extracellular matrix adhesion, which can affect tumor cell dynamics, including adhesion, migration, survival, and other biological processes [17]. Research suggests that the expression levels of integrin $\beta 1$ is mainly regulated by its internalization cycle itself. Integrin $\beta 1$ internalization cycle involves three major processes: 1) Endocytosis by plasma membrane, 2) Shuffling of integrin $\beta 1$ to internal circulation particles, and 3) translocation back to the plasma membrane $[18,19]$. In the whole process of internalization cycle, a considerable load of the internalized integrin $\beta 1$ will be transferred to the intracellular polycystic particles and degraded in the lysosomes [20,21]. The molecules that have, thus far, been found to be involved in the regulation of integrin $\beta 1$ internalization cycle include: Syntaxin [18], plasmalemme neuraminidase (NEU3) [20], and the adaptin Numb [22]. Numb, also referred to as cell fate determinant, is a type of phospho-tyrosine binding (PTB) domain-containing protein connected to intracellular membranes. Numb is involved in many important physiological and pathological processes, such as cell differentiation, proliferation, apoptosis, regeneration, and tumorigenesis. Studies have shown that Numb interacts with integrin $\beta 1$ through its PTB domain and affects the cell adhesion by dictating the position of integrin $\beta 1$ internalization [23]. Numbl is the analogue of Numb homologue. It is a 609 amino acid-long protein and its expression exhibits high tissue specificity. Numbl is mainly distributed in the embryo, adult brain, nerve tissue, muscle cells and peripheral lymphocytes [24]. Numbl and Numb possess the same PTB domains. By using a twohybrid yeast technique, Bogdanovic Ozren [25] and others have demonstrated that PTB domain of Numbl can also interact with integrin $\beta 1$ and coordinate its internalization transfer process in the cells. This suggests that Numbl, in some contexts, functions in a manner similar to Numb. Additional studies have shown that PTB domain structure, combined with integrin $\beta 1$, can contribute to the internalization and lysosomal degradation of integrin $\beta 1$ [25].

Research into the underpinnings of CAM-DR revealed that when tumor cells adhere to the extracellular matrix or stromal cells, the cell cycle arrests in G0/G1 phase, thereby preventing tumor cells from completing the cell cycle. Such relatively quiescent state of tumor cells have been shown to neutralize the cytotoxic effects of drugs, leading to insensitivity or resistance towards chemotherapy drugs $[7,26,27]$. Studies have shown that cell cycle arrest is closely related to an increase in the protein levels of cell cycle negative regulatory factor $\mathrm{p} 21^{\mathrm{WAF} / \mathrm{Cip}}, \mathrm{p} 27^{\mathrm{Kip} 1}$ during the development of CAM-DR in tumor cells [28]. In the model of CAM-DR in mantle cell lymphoma, we found that when malignant cells adhered to the bone marrow stromal cell line, HS-5, the p2 $7^{\text {Kip } 1}$ ubiquitination degradation significantly reduced the accumulation of p27 ${ }^{\text {Kip } 1}$ and the cell cycle arrest was triggered by an increase in $\mathrm{p} 27^{\mathrm{Kip} 1}$ protein levels [29]. Furthermore, 
intracellular accumulation of $\mathrm{p} 27^{\mathrm{Kip} 1}$ induced by the binding between soluble extracellular matrix and cancer cell integrin receptors led to CAM-DR development [30]. Papers have also demonstrated that in addition to altering the cell cycle, integrin $\beta 1$ can activate the downstream corresponding signal pathways during the process mediating cell adhesion. This includes focal adhesion kinase (FAK), integrin-link kinase, and phosphatidylinositol 3-kinase (PI3K) / protein kinase B (PKB/AKT) [31-33]. The activation of these processes synergistically lead to the development of tumor cell resistance to chemotherapeutic agents $[34,35]$.

In summary, Numbl plays a significant role in the formation of CAM-DR in MM cells. Based on previous work, we have drawn the following hypothesis: During the process of MM cell adhesion, distinct Numbl binding domains regulate spatio-temporal distribution and expression levels of integrin $\beta 1$, resulting in arrest of cell cycle and triggering the corresponding signaling pathways that lead to the occurrence CAM-DR in MM cells.

\section{Methods \\ Cell cultures}

RPMI 8226 and H929 human multiple myeloma (MM) cell lines and HS-5 bone marrow stromal cell line were obtained from Chinese Academy of Sciences (Shanghai, China). RPMI 8226, and H929 MM cell lines and HS-5 cell line were cultured in RPMI 1640 medium (GibCo BRL, Grand Island, NY, USA) and in F12 medium (GibCo BRL, Grand Island, NY, USA) respectively. Each media were supplemented with 10\% fetal bovine serum (FBS)(Hyclone, ThermoFisher Scientific, Waltham, MA, USA), 2 mM L-glutamine (GibCo BRL, Grand Island, NY, USA), and $100 \mathrm{U} / \mathrm{mL}$ penicillin-streptomycin mixture (GibCo BRL, Grand Island, NY, USA) at $37^{\circ} \mathrm{C}$ and $5 \% \mathrm{CO} 2$.

\section{Adhesion assays}

RPMI 8226 and H929 cells adhesion assay was performed following instructions by Damiano et al. (1999) [36]. HS-5 cells were seeded at $1 \times 106$ cells $/ \mathrm{ml}$ and incubated at $37^{\circ} \mathrm{C}$ and $5 \% \mathrm{CO} 2$ overnight before being washed 3X in serum-free RPMI1640 medium. RPMI 8226 and H929 cells were plated with HS- 5 cells for $2 \mathrm{~h}$ in serum-free RPMI 1640 medium. Non-adhered cells were then removed but adhered cells were further incubated overnight in RPMI 1640 supplemented media.

To assess adhesion rate [37, 38], RPMI 8226 and H929 cells were labeled with $5 \mathrm{uM}$ of Calcein-AM (Santa Cruz Biotechnology, CA, USA) for 30 mins, washed and incubated an additional $45 \mathrm{~min}$ to ensure that unbound dyes diffuse out of the cells. Next, labeled cells were washed $3 \mathrm{X}$ with phosphatebuffered saline (PBS) then incubated for $2 \mathrm{~h}$. Finally, the absorbance was read out by Multiskan MK3 (ThermoFisher Scientific, USA) at the wavelength of $490 \mathrm{~nm}$ for $3 \mathrm{X}$.

\section{Western blot analysis}

To measure the relative preponderance of proteins of interest using Western Blot (WB), we followed an optimized protocol. Cell lysates were homogenized in lysis buffer (50 $\mathrm{mM}$ Tris- $\mathrm{HCl}$ (pH 7.4), $120 \mathrm{mM} \mathrm{NaCl}, 0.5 \%$ Nonidet P-40, $100 \mathrm{mM} \mathrm{NaF}, 200 \mathrm{M} \mathrm{Na} 3 \mathrm{VO}$, and protease inhibitor mixture), then centrifuged at $8000-10,000 \mathrm{rpm}$ for $30 \mathrm{~min}$ to collect the supernatant at $4{ }^{\circ} \mathrm{C}$. The whole-cell lysates were subjected to $10-12 \%$ gradient polyacrylamide gels and transferred to Polyvinylidene Fluoride (PVDF) membrane (03010040001, Rocho, UK). After blocking with 5\% nonfat milk for $1 \mathrm{~h}$ at room temperature, the primary antibodies were incubated overnight at $4{ }^{\circ} \mathrm{C}$. After 3 times washes $(5$ $\mathrm{min} /$ wash) in PBST (PBS containing 0.1\% Tween-20), the membrane was then incubated with HRP-labeled secondary antibody for $2 \mathrm{~h}$ at room temperature about $25^{\circ} \mathrm{C}$. Then the enhanced chemiluminescent (ECL) detection systems developed the membrane. All the antibodies utilized in this study with the details as follows: anti-Numbl (anti-rabbit, 1:1000, Sigma-Aldrich), anti-Integrin $\beta 1$ (anti-mouse, 1:1000, SigmaAldrich), anti-P27kip1 (anti-rabbit, 1:500, Santa Cruz Biotechnology), anti-CDK2 (anti-rabbit, 1:500, Santa Cruz Biotechnology), anti-GFP (anti-rabbit, 1:500, Santa Cruz Biotechnology), anti-HA (anti-mouse, 1:500, Santa Cruz Biotechnology), cleaved-caspase 3 (anti-rabbit, 1:500, Santa Cruz Biotechnology), anti-Bcl 2 (anti-mouse, 1:500, Santa Cruz Biotechnology), anti-GAPDH (anti-rabbit, 1:1000, Sigma), anti-AKT (anti-rabbit, 1:1000, Cell Signaling), anti-p-AKT (anti-rabbit, 1:1000, Cell Signaling), anti-FAK (anti-rabbit, 1: 1000, Cell Signaling) and anti-p-FAK (anti-rabbit, 1:1000, Cell Signaling).

\section{Immunofluorescence staining}

MM cells were collected and washed twice with -cold PBS, and incubated for $10 \mathrm{~min}$ at $4{ }^{\circ} \mathrm{C}$ in Triton X-100 lysis buffer (30 mM Tris- $\mathrm{HCl} \mathrm{pH} 7.5,150 \mathrm{mM} \mathrm{NaCl}, 25 \mathrm{mM} \mathrm{NaF}, 1 \%$ Triton X-100, 10\% glycerol, $2 \mathrm{mM}$ Naorthovanadate). MM Cells were immobilized for 20 min with cold PBS containing $4 \%$ formaldehyde (Sigma Aldrich), permeabilized with 0.1\% Triton X-100 for $10 \mathrm{~min}$, and then incubated for $2 \mathrm{~h}$ at $4{ }^{\circ} \mathrm{C}$ in $1 \%$ BSA. Then the cells were incubated with primary antibodies at $4{ }^{\circ} \mathrm{C}$ overnight. After washing in PBS, cells was incubated with appropriate sheep FITC- or TRITCconjugated secondary antibodies (1:250; Jackson ImmunoResearch Laboratories) for $2 \mathrm{~h}$ at RT. Sections were washed in PBS and counterstained with DNA stains using 4'6-diamidino-2-phenylindole dihydrochloride (Dapi, Sigma). Finally, cells were reversed on glass slides with glycerol and PBS (1: 1). Immunolabeled cells were examined under a Leica Confocal Laser Scanning Microscope and fluorescence microscope. The following antibodies were used for immunofluorescence: anti-integrin- $\beta 1$ at 1:300 (MAB1981, Chemicon); anti-Numbl at 1:200 (ab37500, abcam). 


\section{Plasmids and transient transfection}

The full-length human Numbl (GenBank no. NM_004756.3) and human ITGB-1 (GenBank no. NM_001113770.1) cDNA were isolated from the cDNA library. For RNA interference (RNAi), sequences targeting the Numbl (AAGGCAAAGC CACTGTAGAGA) were cloned into the pCDNA6.2-GW/ enhanced green fluorescent protein-micro RNA vector, as per the instruction manual (Invitrogen, Carlsbad, CA). Scrambled RNA oligonucleotides were used as controls. For each well, $33.3 \mathrm{nM}$ of each of the three oligos were transfected using Lipofectamine 2000 (Invitrogen, Carlsbad, CA) according to the manufacturer's instructions. The medium was replaced after $6 \mathrm{~h}$ of incubation with RPMI 1640 containing 10\% FBS. After at least $48 \mathrm{~h}$, transfected cells were used for the subsequent experiments.

\section{Co- immunoprecipitation and immunoblotting}

MM cells were collected and lysed in RIPA buffer in ice for the immunoprecipitation assays. After preclearance with $20 \mu \mathrm{l}$ protein G Sepharose beads (Roche, Basel, Switzerland) for $1 \mathrm{~h}$ at $4{ }^{\circ} \mathrm{C}$, cell lysates were incubated with the anti-Numbl and anti-Integrin $\beta 1$ bound to either protein A or G Sepharose beads rotating for $12 \mathrm{~h}$ at $4{ }^{\circ} \mathrm{C}$. Then the precipitated immune complexes were washed with RIPA lysis buffer at least 4 times, eluted by boiling in $2 \times$ SDS sample buffer, separated by SDS-PAGE gel, and analyzed using enhanced chemiluminescence system.

\section{Cell cycle analysis}

To analyze cell cycle of MM cells, cells were first collected and fixed in $70 \%$ ethanol for $1 \mathrm{~h}$ at $4{ }^{\circ} \mathrm{C}$, then incubated with RNase A ( $1 \mathrm{mg} / \mathrm{mL}$, sigma, USA) for 30 min at $37^{\circ} \mathrm{C}$ incubator. Subsequently, cells were stained with $50 \mathrm{mg} / \mathrm{mL}$ propidium iodide (PI) (Becton-Dickinson, San Jose, CA, USA) in PBS, 0.5\% Tween-20, and analyzed using a Becton-Dickinson flow cytometer BD FACScan (Becton-Dickinson, USA).

\section{Flow cytometry-based Annexin V/PI staining}

The flow cytometric analysis was performed to analyze the extent of both apoptosis and necrosis of MM cells using an ApoScreen Annexin V-FITC kit (Southern Biotechnology, Birmingham, AL, USA), according to the manufacturer's protocol. In brief, RPMI 8226 and H929 cells were washed and resuspended in cold binding buffer [10 mM N-2-hydroxyethylpiperazine-N-ethane-sulphonicacid (HEPES), pH 7.4, $140 \mathrm{mM} \mathrm{NaCl}, 2.5 \mathrm{Mm} \mathrm{CaCl} 2$, $0.1 \% \mathrm{BSA}$ ] at cell concentrations between $1 \times 106$ and $1 \times$ 107 cells $/ \mathrm{ml}$. After washing, $10 \mu \mathrm{l}$ labeled annexin $\mathrm{V}$, $380 \mu \mathrm{l}$ binding buffer and $10 \mu \mathrm{l}$ PI solution were added to the cell suspension in sequence on ice. Subsequently, the number of stained cells was measured via flow cytometry BD FACScan (Becton Dickinson, San Jose, CA, USA) and analyzed by FlowJo 10.

\section{Drug cytotoxicity assay}

For drug cytotoxicity assays, MM cells were washed once and adhered to FN or stromal cells, as previously described [39]. In our preliminary experiment [39], the proper drug concentration needed to induce apoptosis in our cell lines had already been established. The viability of MM cells following addition of Doxorubicin, Mitoxantrone or Dexamethasone, at varying concentrations $(1 \mu \mathrm{M}, 2 \mu \mathrm{M}$ and $0.05 \mu \mathrm{M})$, for $72 \mathrm{~h}$, was assessed using Cell Counting Kit-8 (CCK8) assay and trypan staining (*, $P<0.05$ compared with the group of control). For drug exposure, after $24 \mathrm{~h}$, drugs or vehicle control were added to each well and incubated for an additional $72 \mathrm{~h}$, after which the medium containing drugs was removed and the suspended and attached MM cells were collected.

To evaluate cell viability, cells were seeded on a 96-well cell culture cluster (Corning Inc., Corning, NY) at a concentration of $5 \times 10^{4} /$ well in a volume of $1 \mathrm{~L}$ and were grown overnight. CCK8 reagents (Dojindo, Kumamoto, Japan) were added to the different subset wells and the cells were incubated at $37^{\circ} \mathrm{C}$ and $5 \% \mathrm{CO}_{2}$. The absorbance

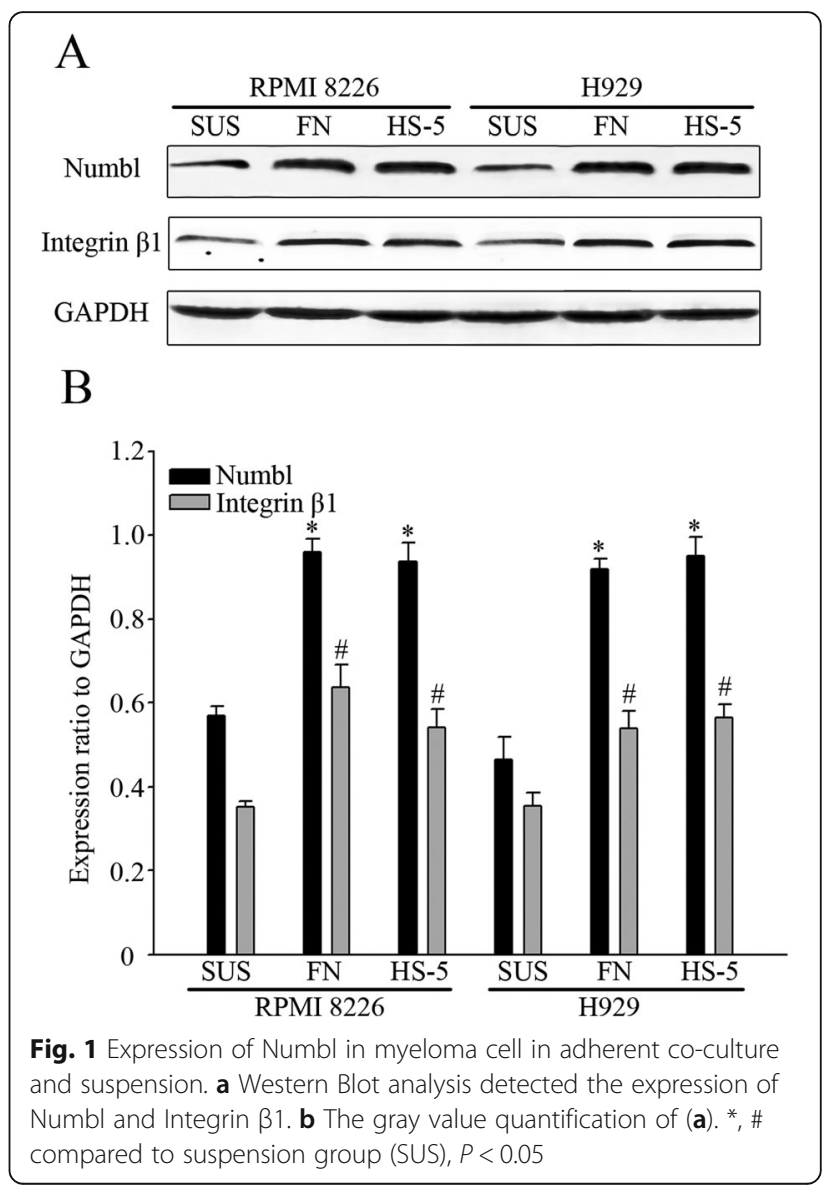


was quantified using an automated plate reader at a test wavelength of $450 \mathrm{~nm}$ for at least three times.

\section{Statistical analysis}

All experiments were repeated at least three times. All numerical data are described as mean \pm SD. Data was analyzed using the two-tailed $t$ test. A $P$ value <
0.05 was considered statistically significant in all of the analyses.

\section{Results}

The expression of Numbl during MM cell adhesion to HS5 cells or FN

Initially, we co-cultured two independent types of human multiple myeloma cell lines, namely, RPMI-8226 and

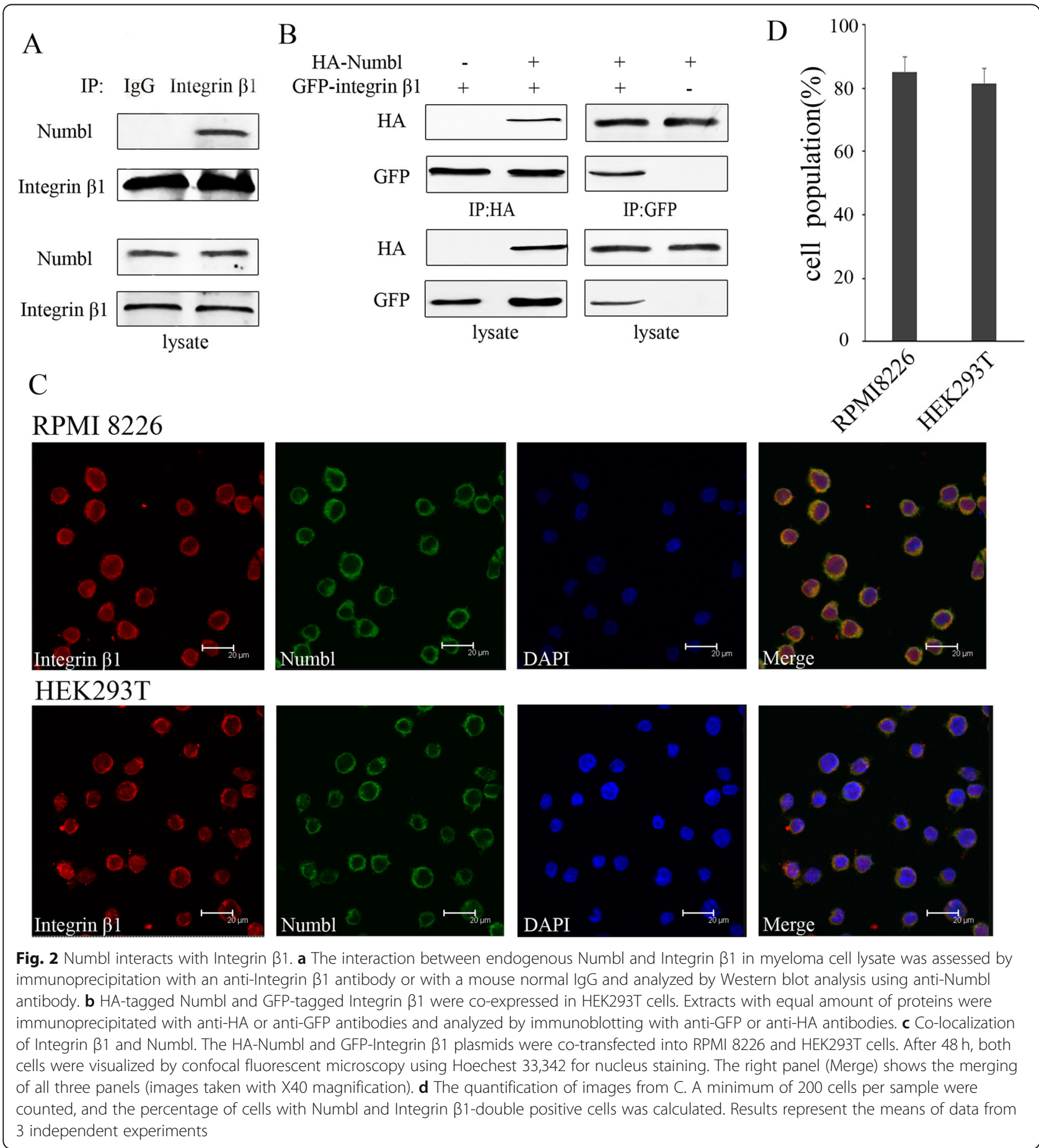


H929, with either a bone stromal cell line, HS-5, or fibronectin (FN). An MM cell suspension culture was used as a control. As shown in Fig. 1, the expression of Numbl and Integrin $\beta 1$ were increased when RPMI-8226 or H929 cells adhered to FN or HS-5 cells in co-cultures.

\section{Numbl interacts with integrin $\beta 1$}

To determine whether Numbl interacted with Integrin $\beta 1$ in vivo, we performed a co-immunoprecipitation experiment. The results revealed that Numbl positively interacted with Integrin $\beta 1$ (Fig. 2a). Furthermore, when HA-tagged Numbl and GFP-tagged Integrin $\beta 1$ were transfected into HEK293T cells, we detected Numbl presence in the GFP-tagged Integrin $\beta 1$ immunoprecipitates (Fig. $2 b$ left). Similarly, GFP-labeled Integrin $\beta 1$ was also detected in HA-tagged Numbl immunoprecipitates
(Fig. 2b right). Next, we performed confocal microscopy on immunolabeled cells and showed that both Numbl and Integrin $\beta 1$ are expressed in the cytoplasm, further attesting to the possibility that they may interact. These results suggest that Numbl can modulate the spatial distribution of Integrin $\beta 1$, at least, in the cytoplasm (Fig. 2c).

\section{Domains involved in the Numbl-Intergin $\beta 1$ interaction}

The PTB domain proteins, Numbl and Numb, have been described as essential adaptors for clathrin-mediated integrin endocytosis [25]. To further understand the association between Numbl and Intergin $\beta 1$, we sought to identify which regions in these two proteins were involved in mediating their physical interaction. Numbl contains a phosphotyrosine binding region (PTB), a coiled-coil domain $(\mathrm{CC})$, and a Phe-rich segment. We
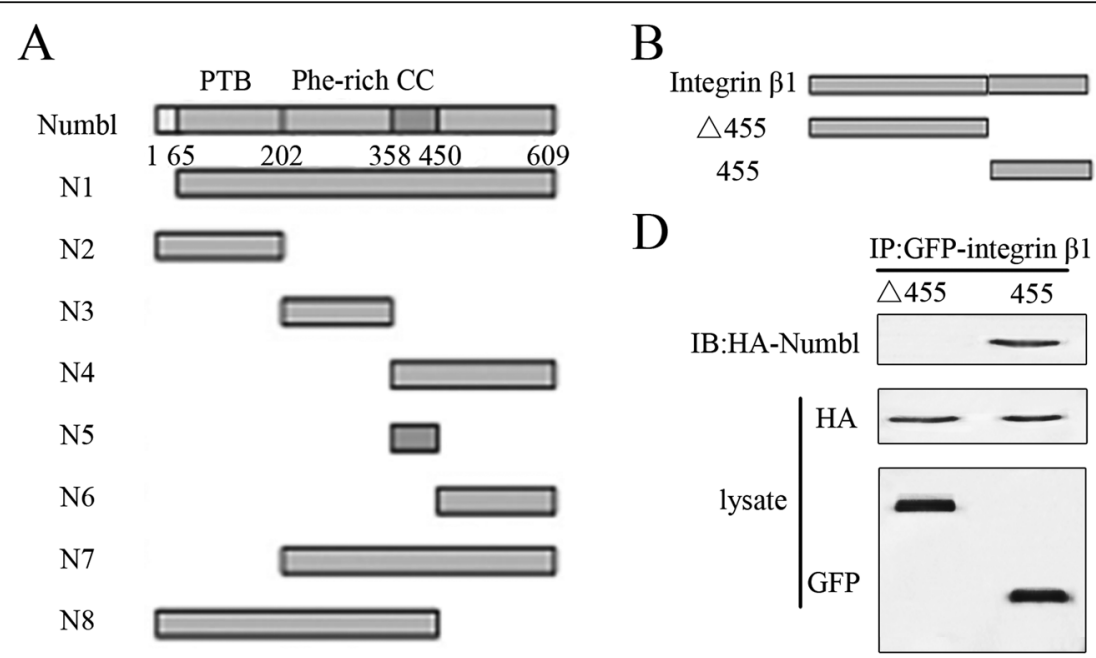

$\mathrm{C}$

IP:HA-Numbl

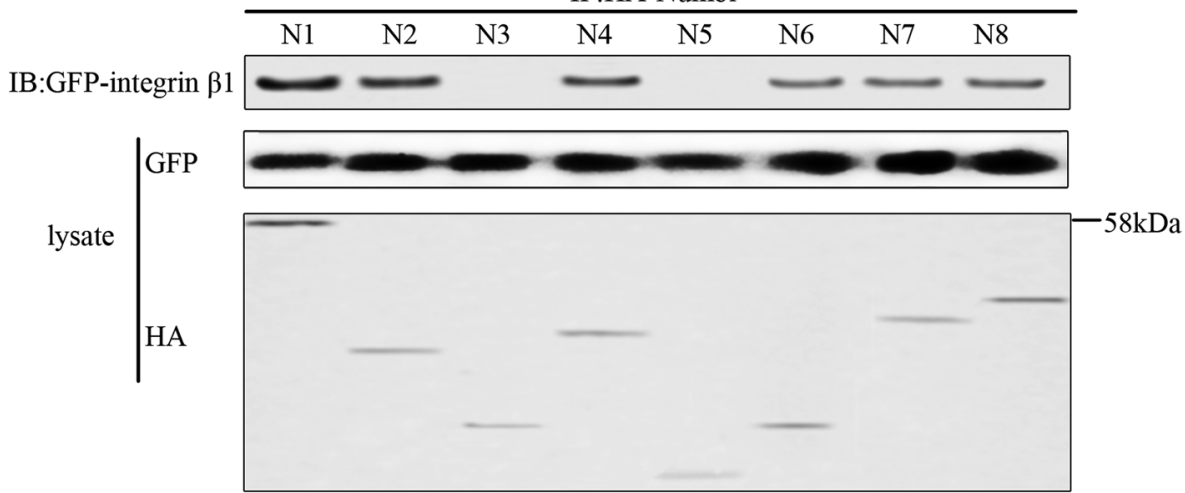

Fig. 3 Identification of domains required for the interaction between Numbl and Integrin $\beta 1$. a A schematic presentation of designed human Numbl derivatives. Numbl contains a phosphotyrosine binding region (PTB), a coiled-coil domain (CC), and a Phe-rich segment. b Schematic diagram of Integrin $\beta 1$ gene and domain. c Two regions of Numbl are involved in its interaction with Integrin $\beta 1$. HEK293T cells were cotransfected with GFP-Integrin $\beta 1$ and HA-Numbl derivatives. Cell lysates were immunoprecipitated with anti-HA antibody and analyzed by Western blots with anti-GFP antibody. d A short N-terminal fragment (amino acids: 455-802) is required for binding with Integrin $\beta 1$. HEK293T cells were transfected with the indicated expression plasmids. Immunoprecipitation and Western Blot analysis were performed using indicated antibodies 
constructed truncation mutants of Numbl and Intergin $\beta 1$ (Fig. 3a). The truncated mutants of Numbl and Intergin $\beta 1$ were co-transfected into HEK293T cells, and the cell extracts were subsequently subjected to coimmunoprecipitation. Our data reveals that six Numbl mutants (N1, N2, N4, N6, N7, N8) can interact with the full-length Intergin $\beta 1$ (Fig. 3c). By performing domain analysis, we found that mutants that contain PTB domain or C-terminal fragment of Numbl were capable of binding to Integrin $\beta 1$. As for the Integrin $\beta 1$ protein, a short N-terminal fragment (amino acid residues: 455802), was sufficient for binding to Numbl (Fig. 3b).

\section{Numbl regulates the expression of integrin $\beta 1$ and promotes MM cell adhesion to HS-5}

Since Numbl was found to interact with Integrin $\beta 1$, we next investigated the functional outcome of this interaction on MM cell adhesion. Full-length Numbl or RNAi were used to transfect either RPMI 8226 or H929 cell lines (Fig. 4). Furthermore, we confirmed which domains of Numb1 were responsible for the positive effect on Integrin $\beta 1$ expression. Compared with full-length Numbl, overexpression of the mutant N8 (lacking Cterminal domain) did not increase Integrin $\beta 1$ expression while specific knockdown of endogenous Numbl with RNAi markedly attenuated the expression of Integrin $\beta 1$ (Fig. 4a). We also detected the effect of mutants N3 and N5 that did not bind to Integrin $\beta 1$. Negither of the mutants worked on Integrin $\beta 1$ (Additional file 1: Figure $\mathrm{S} 1 \mathrm{~A})$. These results confirm that Numbl regulates the expression of Integrin $\beta 1$ through the $\mathrm{C}$-terminal fragment rather than the PTB domain. Furthermore, we questioned whether overexpression of Numbl influences myeloma cell adherence to HS-5 cells or to FN. To this end, we used Calcein-AM test to assess cell adhesion in 96-cell plates and a microplate reader was used for measurement. As was shown in Fig. 5b and c, overexpression of full-length Numbl and N7( $\triangle \mathrm{PTB})$ caused more cells to adhere to HS5 cells and FN, whereas overexpression of N8 did not affect adherence. So do N3 and N5 (Additional file 1: Figure S1B). Moreover, knockdown of endogenous Numbl reduced further myeloma cell adhesion compared to control group. Since mutant N8 could bind to Integrin $\beta 1$ without impacting the protein levels, we decided to use $\mathrm{N} 8$ as the dominant negative mutant of full-length Numbl in the ensuing experiments.

\section{Numbl promotes the drug resistance in MM cells}

The observation that Numbl promotes adhesion of MM cells to FN and also physically associates with Integrin $\beta 1$ led us to examine whether Numbl could enhance CAM-DR development observed in MM cells. To test this hypothesis, RPMI 8226 and H929 cells were treated with Doxorubicin (Dox), mitoxantrone (Mito) and dexamethasone (Dexa) in the presence and absence of HS-5 cells or FN. As expected, when RPMI 8226 and H929 cell adhere to FN or HS-5 cells, MM cell viability was increased with the addition of chemotherapeutic drugs (Fig. 6a). Furthermore, to detect whether Numbl plays a role in the progress of CAM-DR in cells, RPMI 8226 and H929 cells, with altered Numbl expression levels, were treated with Dox, Mito, Dexa respectively, as indicated above. While overexpression of Numbl significantly protected MM cell from Dox-induced cell death in HS-5 cells or FN coated plates, suppressing the intrinsic expression of Numbl using specific siRNAs enhanced

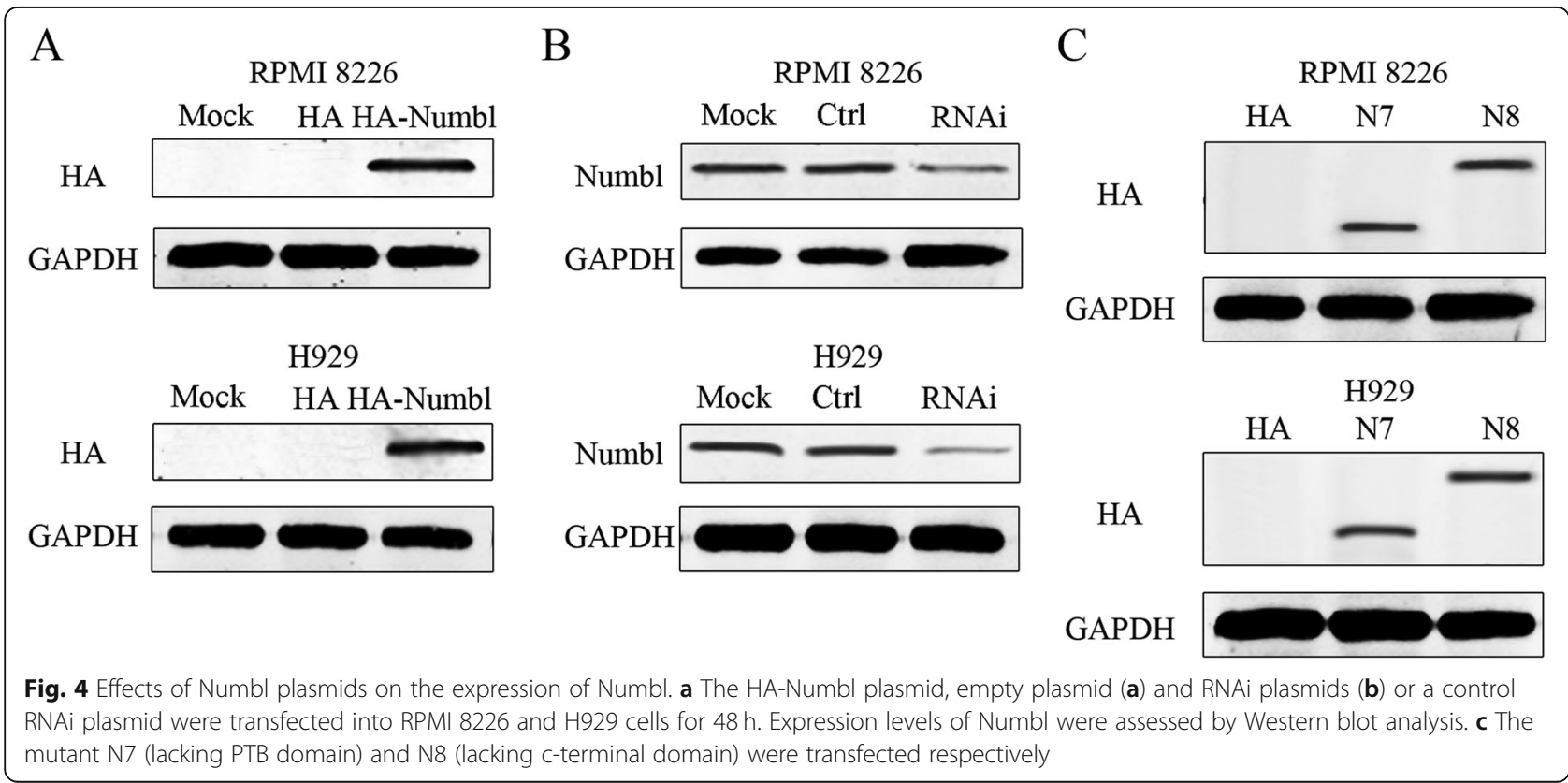




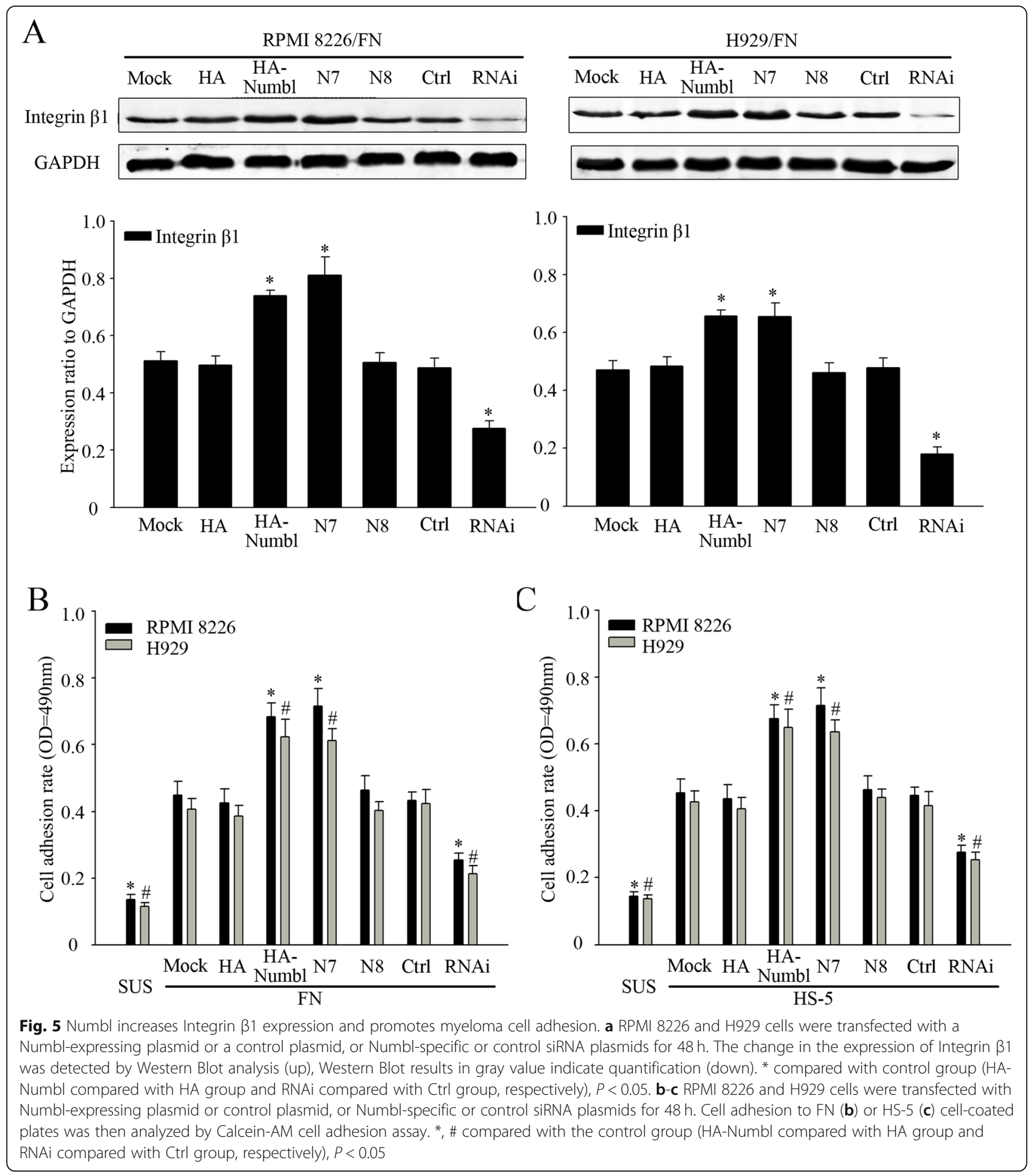

MM cell death upon Dox treatment (Fig. 6b). Similarly, Numbl overexpression promoted MM cell survival after treatment with Mito or Dexa(Fig. 6c and d). To assess whether Numbl promoted the survival of chemotherapeutics-treated MM cells via Integrin $\beta 1$, we studied the role of mutant N8 (with absent C-terminal domain). As shown in Fig. 7a, overexpression of $\mathrm{N} 8$ by
MM cells could not increase their viability after treatment with chemotherapeutic drugs. Overexpression of $\mathrm{N} 3$ and N5 that did not bind to Integrin $\beta 1$ also couldn't protect cells against chemotherapeutic drugs (Additional file 1: Figure S1C).

To test directly whether Numbl-induced drug resistance of MM cells was due to inhibition of apoptosis, 


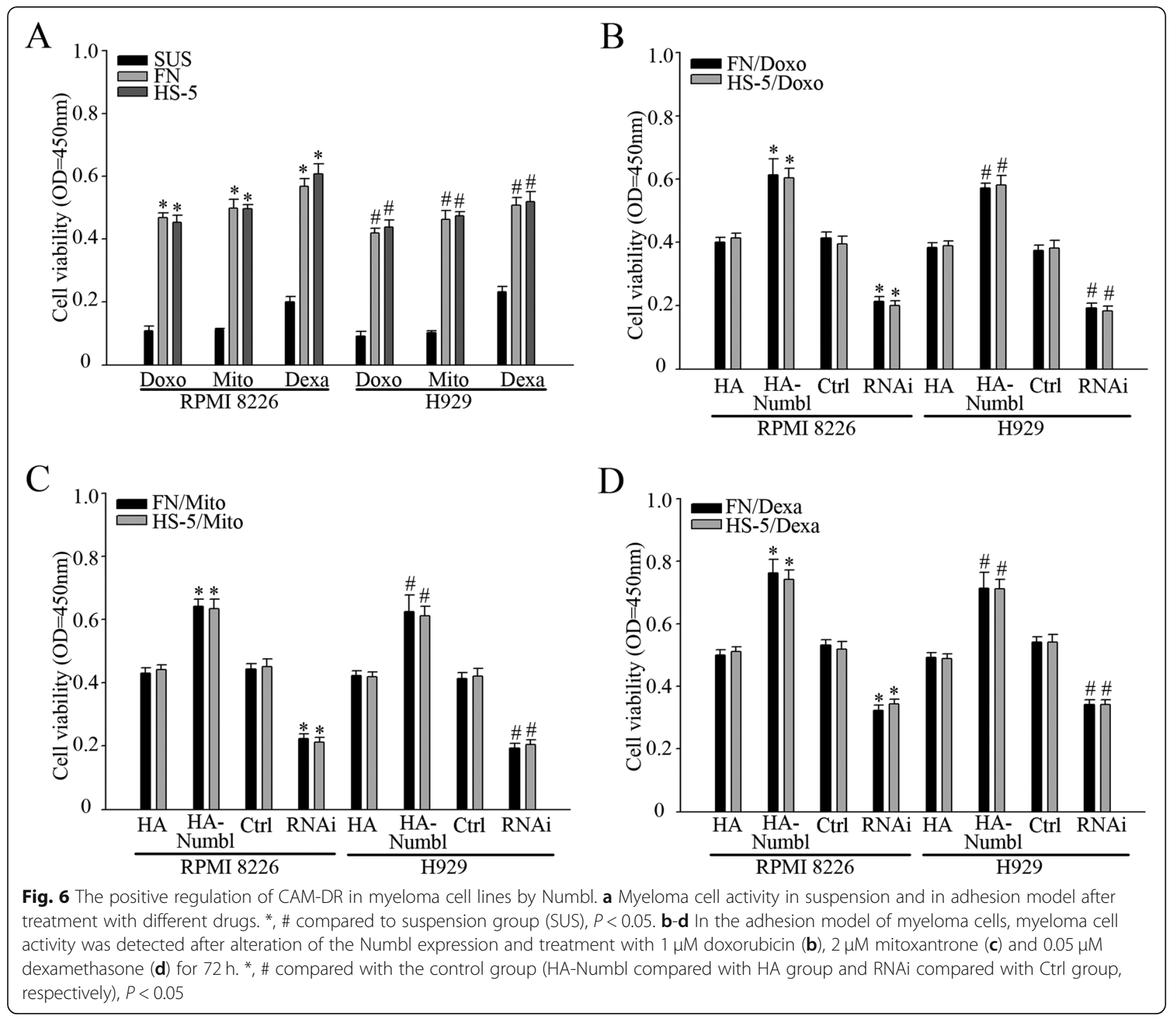

MM cells overexpressing Numbl were treated with Dox in the presence of HS-5 cells, before being harvested for $\mathrm{WB}$ and Annexin $\mathrm{V}$ analysis. Compared with the vector control and mutant N8 transfection, full-length Numbl transfected cells had significantly lower expression levels of anti-apoptotic protein, BCL2, and lower cell apoptosis in the presence of HS-5 cells. While mutant N3 did not act on myeloma cell apoptosis (Additional file 1: Figure S1D). In contrast, silencing of Numbl markedly raised the expression of cleaved-caspase 3 and the number of Annextin V positive cells (Fig. 7c). Taken together, these results indicate that Numbl specifically promotes MM cell drug-resistance, likely through the alteration of Integrin $\beta 1$ expression, leading to inhibition of apoptosis.

\section{Numbl affect cell cycle through the interaction with integrin $\beta 1$}

We were interested to further define the mechanisms by which Numbl contributes to the CAM-DR induction. Previous studies demonstrated that cell adhesion to FN may induce cell cycle arrest and protect tumor cells from chemotherapeutic drug-induced apoptosis [2, 5, 7]. First, we analyzed the cell cycle distribution of MM cells in suspension and in adhesion conditions. Flow cytometric analysis showed that $\mathrm{MM}$ cells adhering to $\mathrm{FN}$ or HS-5 cells remained in G0/G1 phase. (Fig. 8a, c). Consistently, we detected the expression of proteins that regulate the cell cycle progression in G0/G1 restriction point. As expected, a significantly elevated level of p27 ${ }^{\text {kip1 }}$ was detected in adherent cells, whereas CDK2 was downregulated (Fig. $8 \mathrm{~b}$ and d). Next, we sought to 


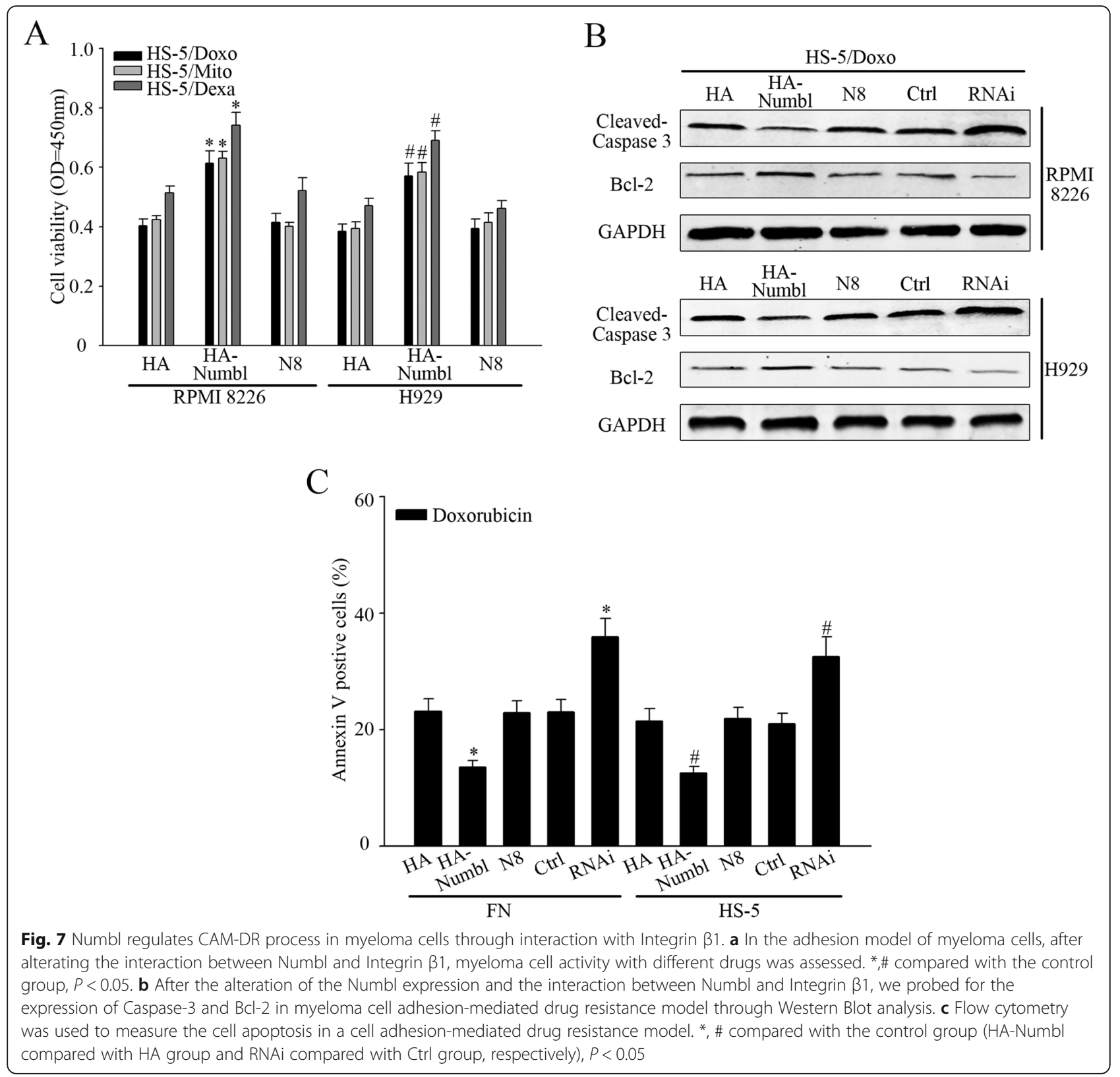

determine whether Numbl expression could affect the cell adhesion-mediated cell cycle arrest. As shown in Fig. 9a and b, flow cytometric analysis revealed that overexpression of Numbl triggered FN-adherent MM cells to be arrested in the G0/G1 phase (72.7\% of the cells). In comparison HA group resulted in only $53.2 \%$ of cells arrested in the G0/G1 phase. And the effect of N3 group was similar with HA group(Additional file 1: Figure S1E). Complete suppression of Numbl led to even less cells arrested in the G0/G1 phase (41.8\%) compared to the Ctrl group (54.1\%). Cell cycle related proteins $\mathrm{p} 27^{\mathrm{kip} 1}$ and CDK2 expression were consistent with the above data trend (Fig. 9c, d). Given these data, we propose that Numbl might be involved in cell cycle regulation through an interaction with Integrin $\beta 1$. Indeed, a comparison of the effect of the full length Numbl and the mutant Numbl (N8) on cell cycle regulation showed that mutant N8 had no effect on cell cycle distribution (56.1\%) and was comparable to control. However, the full length Numbl achieved $70.8 \%$ of cell arrest in the G0/G1 phase (Fig. 10a). These data were confirmed with Western Blot analysis (Fig. 10b).

\section{Numbl regulates activation of signaling pathways through interaction with integrin $\beta 1$}

FAK/Src has been shown to activate phosphoinositide 3kinase (PI3K) and Akt has been shown to promote cell adhesion and survival $[40,41]$. As such, the activation of FAK and the PI3K/AKT signaling pathways were examined 


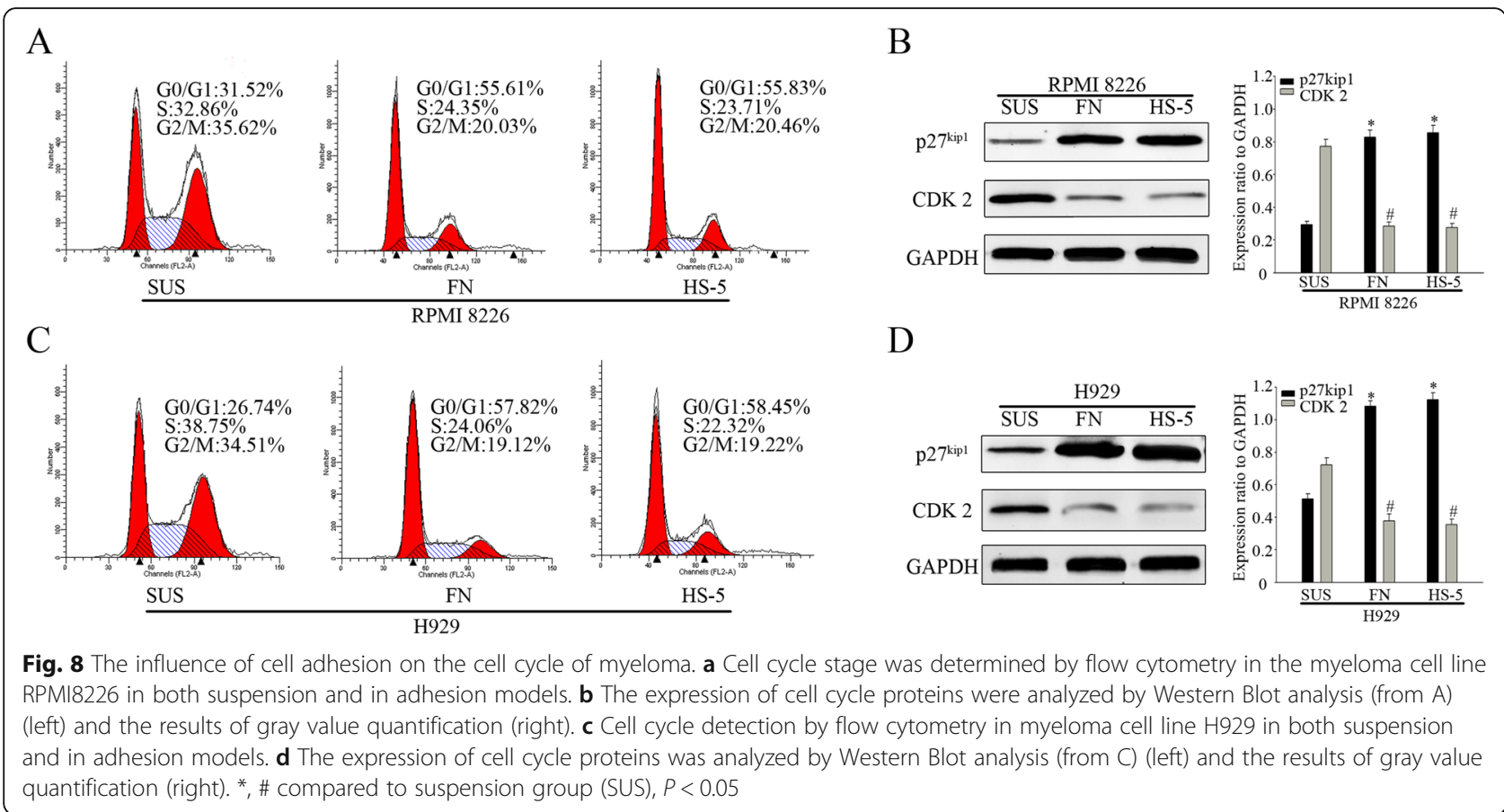

in the MM cell adhesion model. The results showed that these signaling pathways were indeed activated (Fig. 11a). By altering the expression of Numbl, we showed that Numbl could regulate the activation of these signaling pathways (Fig. 11b). In order to further test the hypothesis that high expression of Numbl could influence the activation of signaling pathways, we treated MM cells with a PI3K inhibitor (LY294002) after Numbl overexpression. Treatment with LY294002 reversed the enhanced activity of the cell signaling pathways (Fig. 12a). In addition, treatment with LY294002 reversed the increase in the cell adhesion rate and the drug resistance conferred by the high expression of Numbl (Fig. 12b, c). In conclusion, Numbl triggers the activation of cell signaling pathways by regulating Integrin $\beta 1$ in a way to impact the progress of MM cell adhesionmediated drug resistance.

\section{Discussion}

MM, also known as myeloma, plasma cell myeloma or Kahler's disease, is a progressive malignant tumor. It is mainly characterized by tumor cell accumulation in the bone marrow and secretion of monoclonal immunoglobulins [42]. Although new treatments are continuously being developed, MM remains incurable due to a high recurrence rate, drug resistance following initial treatment, and low sensitivity to chemotherapy and radiotherapy [43, 44]. The average survival time of patients with MM after relapse is about 9 months and resistance to drug is the main obstacle to a consistently effecti ignalingetn $[4,45]$. The relationship between MM cells and bone marrow is a complex network. Bone marrow provides a micro-environment for MM cells to survive in the presence of the disease by mean of a soluble stromal connecting MM cells and mediating the interactions [46]. This also suggests that MM cell adhesion to bone marrow microenvironment or extracellular matrix can induce the resistance to multiple drugmediated apoptosis, a process known as CAM-DR. [6, 45 , 47]. Cell adhesion plays a pivotal role in the process of the resistance to drug mediated apoptosis [48]. Therefore, herein, we describe the development of an in vitro adhesion model simulating in vivo MM cell adhesion to study the role and mechanism of adhesion in mediating CAM-DR.

Numb aa sequence homology to Numbl is high and previous studies have showed that Numbl plays redundant roles with Numb in the regulation of cellular differentiation, proliferation, and fate decision [49-52]. It has been reported that Numb interacts with Integrin $\beta 1$ through its PTB domain and it affects cell adhesion by controlling the internalization and compartmentalization of integrin $\beta 1$ [23]. Therefore, here we sought to investigate whether Numbl interacts in the same way with Integrin $\beta 1$ in myeloma cells. In this experiment, we detected the expression levels of Numbl and Integrin $\beta 1$ when MM cells are co-cultured with either FN or HS-5 stromal cells. Our data revealed that Numbl expression levels were significantly higher in co-cultures than in MM cells cultured alone. This is suggestive of the possibility that Numbl plays a role in CAM-DR development in MM. Subsequently, we confirmed the occurrence of an interaction between endogenous or exogenous 

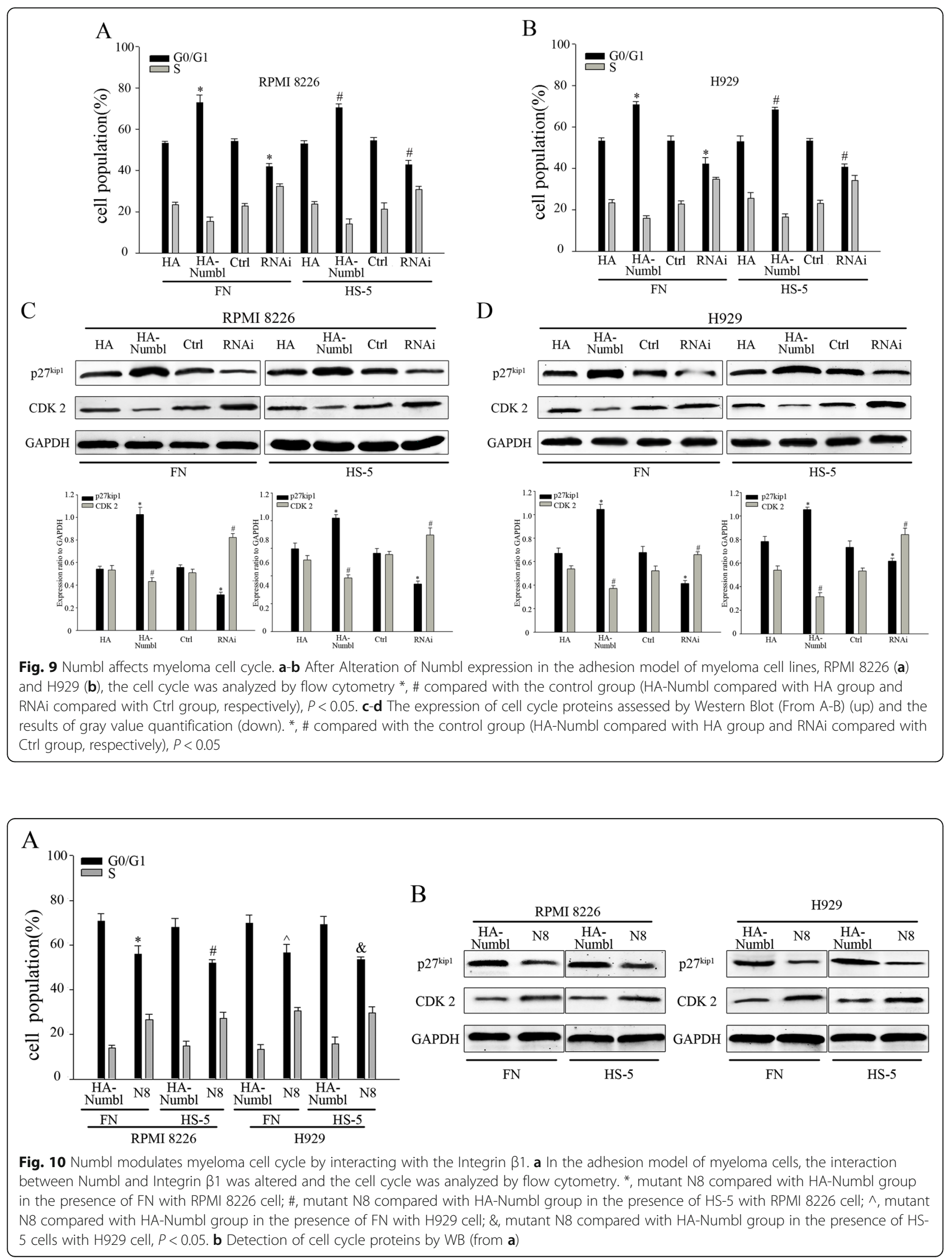

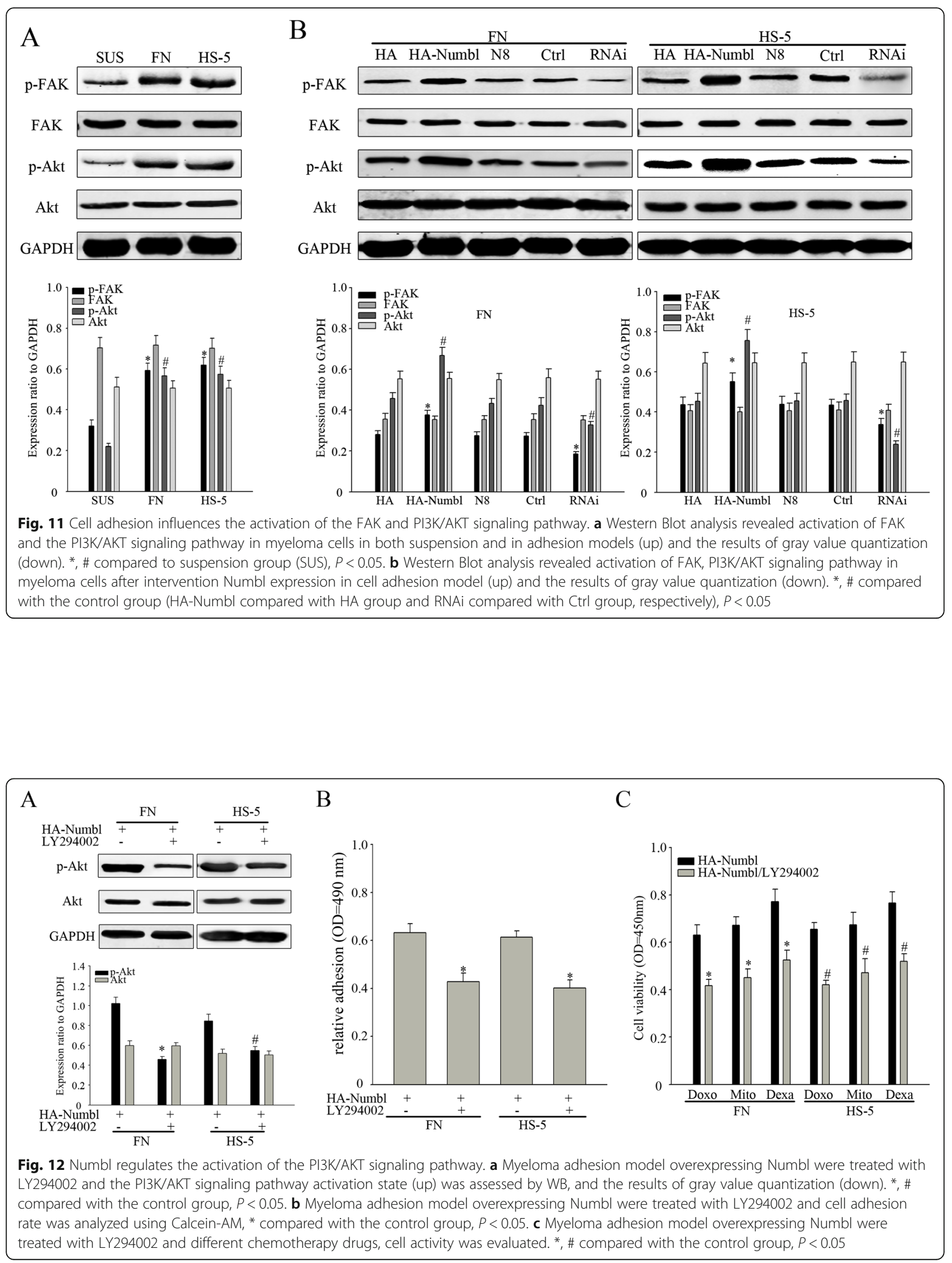
Numbl and Integrin $\beta 1$ in the cells, using CO-IP and immunofluorescent staining assays. In order to further characterize this interaction, we designed truncated mutation plasmid constructs of Numbl and Integrin $\beta 1$. Domain mapping experiments indicated that PTB domain and C-terminal of Numbl are responsible for binding to Integrin $\beta 1$. Indeed, only the expression of full-length and N7 (lacking PTB domain) mutant versions could increase the protein levels Integrin $\beta 1$, whereas expression of N8 (lacking C-terminal domain) mutant had no effect. We hypothesized that the C-terminal domain of Numbl assumes a specific conformation that facilitates Integrin $\beta 1$ binding, while PTB domain cannot. Accordingly, we advanced the idea that the interaction between $C$ terminal domain of Numbl and Integrin $\beta 1$ might be highly important for the development of MM CAM-DR. To test this, we altered Numbl expression and investigated the role of its full length and N8 (C-terminal absence) fragment in adherent myeloma cell with or without chemotherapeutic drug. We have also developed and identified additional truncation mutants of Numbl (N3 and N5) that showed interference with the interaction (Additional file 1: Figure S1). Overall, our data indicates that Numbl promotes drug resistance of MM cells by means of an interaction between the C-terminal domain of Numbl and Integrin $\beta 1$. Here we reported about the expression and the role of Numbl in the progress of MM CAM-DR, however the specific regulation mechanism is yet to be elucidated and warrant further investigations.

Most of the cytotoxic effects of chemotherapy drugs on tumor cells are mediated through targeting a specific cell cycle stage. When tumor cells adhere to extracellular matrix, cell cycle is delayed and cells are in a relatively quiescent state, raising the cell resistance to chemotherapeutic drugs $[7,26,27,48]$. Proteins regulating cell cycle play a key role in the cell cycle progression [28]. We had demonstrated that over-expression of Numbl induced cell cycle arrest in FN-adherent MM cells, whereas, N8 mutant did not. Taken together, these results suggest that Numbl is a negative regulator of cell cycle progression, in part, via association with Integrin $\beta 1$-mediated adhesion. It has been reported that Integrin $\beta 1$ cannot only affect the cell cycle, but it can also activate the downstream corresponding signaling pathways, including FAK and PI3K/AKT pathways, while also mediating cell adhesion. It has been previously reported that phosphorylation of the Focal Adhesion Kinase (FAK) led to the activation of Src/Syk/STAT3 and Akt, which are crucial signaling molecules involved in enhancing cell adhesion and protecting cells from drug-induced cell apoptosis [53]. Activating Integrin $\beta 1 / F A K$ and its downstream Src-Syk-STAT3/Akt signaling pathway can promote enhanced cell adhesion and CAM-DR in MM cells $[53,54]$. In this study, we have shown that overexpression of Numbl promoted the adhesion of myeloma cells to FN or HS-5 cells via activation of Integrin $\beta 1$ FAK and the subsequent activation of Akt pathway, which eventually facilitated the survival and drug resistance of myeloma cells. Indeed, the treatment of MM cells with LY294002, an inhibitor of phosphoinositide 3kinase, decreased the activation of Akt, along with cell adhesion and the cell survival rates after treatment with chemotherapy drugs. Taken together, these results indicate that Numbl promotes the adhesion and CAM-DR of $\mathrm{MM}$ cells by activating Integrin $\beta 1 / \mathrm{FAK}$ and its downstream Akt pathway.

Overall, we have demonstrated that Numbl promotes MM cell adhesion, survival, and drug resistance via its $\mathrm{C}$-terminal domain binding to Integrin $\beta 1$. Subsequently, integrin $\beta 1$ activation leads to FAK phosphorylation, which in turn activates Akt pathway, leading to the promotion of CAM-DR in MM cells. Our findings further highlight the therapeutic potential of targeting the Numbl/Integrin/FAK/Akt axis.

\section{Conclusions}

In a myeloma adhesion model, the expression levels of Numbl and Integrin $\beta 1$ were significantly increased. Numbl affects CAM-DR through regulating Integrin $\beta 1$ activation, which affects the cell cycle and activation of downstream signaling pathway kinase.

\section{Supplementary information}

Supplementary information accompanies this paper at https://doi.org/10. 1186/s12885-019-6446-y.

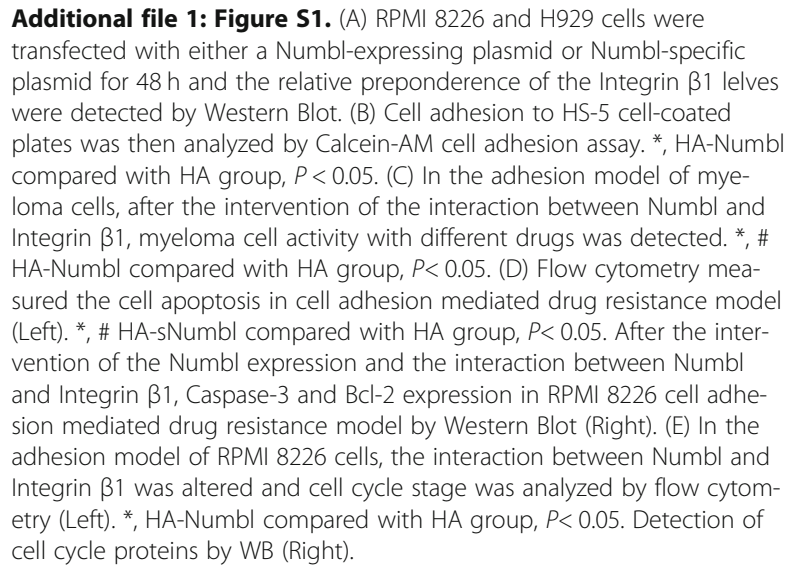

\section{Abbreviations}

CAM-DR: Cell adhesion mediated drug resistance; CC: Coiled-coil domain; CCK8: Cell Counting Kit-8; CO-IP: Co-immunoprecipitation;

Dexa: Dexamethasone; Dox: Doxorubicin; ECL: Enhanced chemiluminescent; EM-DR: Microenvironment mediated resistance; FAK: Focal Adhesion Kinase; FN: Fibronectin; HEPES: N-2-hydroxyethylpiperazine-N-ethane-sulphonicacid; MCL: Mantle cell lymphoma; Mito: Mitoxantrone; MM: Mutiple myeloma; NEU3: Plasmalemma neuraminidase; PI3K: Phosphatidylinositol 3-kinase; 
PKB: Protein kinase B; PTB: Phosphotyrosine binding; PVDF: Polyvinylidene Fluoride; SDS-PAGE: Sodium dodecyl sulfate-polyacrylamide gel electrophoresis; SFM-DR: Soluble cytokines mediated drug resistance

\section{Acknowledgements}

We thank the laboratory team members for their collaboration (Jiangsu Province Key Laboratory for Inflammation and Molecular Drug Target, Medical College of Nantong University).

\section{Authors' contributions}

YW, SH and CC conceived the study. XX and HL provided the clinical knowledge of MM and CAM-DR. YH, XH and JT performed experiments. $X Y$, $L Y$ and $Z D$ arranged the data and performed statistical analysis. $Y H$ wrote the manuscript. All authors have read and approved the final manuscript.

\section{Funding}

This work was supported by the National Natural Science Foundation of China (No.81600158, No. 81670196); the National Funds for Distinguished Young Scientists of Nantong City (No. WQ2016057); the Natural Science Foundation of Jiangsu province Grants (No. BK20160060); the Major Research of Natural Science Foundation for Colleges and Universities in Jiangsu Province (16KJ320004), Six Talent Peaks Project in Jiangsu Province (2015SWYY-021); A Project Funded by the Priority Academic Program Development of Jiangsu Higher Education Institutions (PAPD). The funders had no role in study design, data collection and analysis, manuscript preparation, or submission for publication.

\section{Availability of data and materials}

All data supporting the conclusions have been presented in this manuscript. The corresponding author shall provide the raw data and plasmids as per request.

\section{Ethics approval and consent to participate}

Not applicable.

\section{Consent for publication}

Not applicable.

\section{Competing interests}

The authors declare that they have no competing interests.

\section{Author details}

'Department of Oncology, Nantong University Cancer Hospital, Nantong, Jiangsu 226001, People's Republic of China. ${ }^{2}$ Department of Oncology center, Jiangsu Jiangyin People's Hospital, Jiangyin, Jiangsu 214400, People's Republic of China. ${ }^{3}$ Department of Pathogenic Biology, School of Medicine, Nantong University, Nantong, Jiangsu 226001, People's Republic of China. ${ }^{4}$ Department of Hematology, Affiliated Hospital of Nantong University, Nantong, Jiangsu 226001, People's Republic of China. ${ }^{5}$ Department of Immunology, Medical College of Jiangnan University, Wuxi, Jiangsu 214122, People's Republic of China. ${ }^{6}$ Department of Pathology, Nantong University Cancer Hospital, Nantong, Jiangsu 226001, People's Republic of China.

\section{Received: 14 April 2019 Accepted: 9 December 2019}

\section{Published online: 30 December 2019}

\section{References}

1. De P, Dey N, Terakedis B, Bergsagel PL, Li ZH, Mahadevan D. An integrintargeted, pan-isoform, phosphoinositide-3 kinase inhibitor, SF1126, has activity against multiple myeloma in vivo. Cancer Chemother Pharmacol. 2013;71:867-81

2. Emmons MF, Gebhard AW, Nair RR, Baz R, McLaughlin ML, Cress AE. Acquisition of Resistance toward HYD1 correlates with a reduction in cleaved 4 integrin expression and a compromised CAM-DR phenotype. Mol Cancer Ther. 2011;10:2257-66.

3. Fiserova B, Kubiczkova L, Sevcikova S, Hajek R. Implication of bone marrow microenvironment in pathogenesis of multiple myeloma. Klin Onkol. 2012; 25:234-40.

4. Hazlehurst LA. Cell adhesion to fibronectin (CAM-DR) influences acquired Mitoxantrone resistance in U937 cells. Cancer Res. 2006;66:2338-45.
5. Lwin T, Lin J, Choi YS, Zhang X, Moscinski LC, Wright KL. Follicular dendritic cell-dependent drug resistance of non-Hodgkin lymphoma involves cell adhesion-mediated Bim down-regulation through induction of microRNA181a. Blood. 2010;116:5228-36.

6. Landowski TH, Olashaw NE, Agrawal D, Dalton WS. Cell adhesion-mediated drug resistance (CAM-DR) is associated with activation of NF-KB (RelB/p50) in myeloma cells. Oncogene. 2003;22:2417-21.

7. Hazlehurst LA, Dalton WS. Mechanisms associated with cell adhesion mediated drug resistance (CAM-DR) in hematopoietic malignancies. Cancer Metastasis Rev. 2001;20:43-50.

8. Damiano JS, Hazlehurst LA, Dalton WS. Cell adhesion-mediated drug resistance (CAM-DR) protects the K562 chronic myelogenous leukemia cell line from apoptosis induced by BCR/ABL inhibition, cytotoxic drugs, and gamma-irradiation. Leukemia. 2001;15:1232.

9. Arnaout MA, Goodman SL, Xiong JP. Coming to grips with integrin binding to ligands. Curr Opin Cell Biol. 2002;14:641-51.

10. Berry MG, Goode AW, Puddefoot JR, Vinson GP, Carpenter R. Integrin beta1mediated invasion of human breast cancer cells: an ex vivo assay for invasiveness. Breast cancer (Tokyo, Japan). 2003;10:214.

11. Oshita F, Kameda Y, Hamanaka N, Saito H, Yamada K, Noda K. High expression of integrin beta1 and p53 is a greater poor prognostic factor than clinical stage in small-cell lung cancer. Am J Clin Oncol. 2004;27:215-9.

12. Ke JJ, Shao QS, Ling ZQ. Expression of E-selectin, integrin beta1 and immunoglobulin superfamily member in human gastric carcinoma cells and its clinicopathologic significance. World J Gastroenterol. 2006;12:3609-11.

13. Hazlehurst LA, Argilagos RF, Dalton WS. Beta1 integrin mediated adhesion increases Bim protein degradation and contributes to drug resistance in leukaemia cells. Br J Haematol. 2007;136:269-75.

14. Guo-Bao W, Xiao-Qin C, Qi-Rong G, Jie L, Gui-Nan L. Yue, L arsenic trioxide overcomes cell adhesion-mediated drug resistance through downregulating the expression of $\beta$. Leuk Lymphoma. 2010;51:1090-7.

15. Naci D, El Azreq MA, Chetoui N, Lauden L, Sigaux F, Charron D. 21 integrin promotes Chemoresistance against doxorubicin in cancer cells through extracellular signal-regulated kinase (ERK). J Biol Chem. 2012;287:17065-76.

16. Terol MJ, Lopez-Guillermo A, Bosch F, Villamor N, Cid MC, Campo E. Expression of beta-integrin adhesion molecules in non-Hodgkin's lymphoma: correlation with clinical and evolutive features. J Clin Oncol. 1999;17:1869-75.

17. Hynes RO. Integrins: bidirectional, allosteric signaling machines. Cell. 2002; 110:673-87.

18. Caswell PT, Norman JC. Integrin trafficking and the control of cell migration. Traffic. 2006;7:14-21

19. Riggs KA, Hasan N, Humphrey D, Raleigh C, Nevitt C, Corbin D. Regulation of integrin endocytic recycling and chemotactic cell migration by syntaxin 6 and VAMP3 interaction. J Cell Sci. 2012;125:3827-39.

20. Tringali C, Lupo B, Silvestri I, Papini N, Anastasia L, Tettamanti G. The plasma membrane Sialidase NEU3 regulates the malignancy of renal carcinoma cells by controlling 1 integrin internalization and recycling. J Biol Chem. 2012;287:42835-45.

21. Lobert VH, Brech A, Pedersen NM, Wesche J, Oppelt A, Malerød L. Ubiquitination of a5integrin $\beta 1$ controls fibroblast migration through lysosomal degradation of fibronectin-integrin complexes. Dev Cell. 2010 Elsevier Inc. All rights reserved. 2010;19:148-59.

22. Nishimura T, Kaibuchi K. Numb controls integrin endocytosis for directional cell migration with aPKC and PAR-3. Dev Cell. 2007;13:15-28.

23. Rašin M, Gazula V, Breunig JJ, Kwan KY, Johnson MB, Liu-Chen S. Numb and Numbl are required for maintenance of cadherin-based adhesion and polarity of neural progenitors. Nat Neurosci. 2007;10:819-27.

24. Zhong $W$, Feder JN, Jiang $M$, Jan LY, Jan YN. Asymmetric localization of a mammalian numb homolog during mouse cortical neurogenesis. Neuron. 1996;17:43-53.

25. Bogdanović O, Delfino-Machín M, Nicolás-Pérez M, Gavilán MP, GagoRodrigues I, Fernández-Miñán A. Numb/Numbl-Opo antagonism controls retinal epithelium morphogenesis by regulating integrin endocytosis. Dev CellCopyright (c) 2012 Elsevier Inc. All rights reserved. 2012;23:782-95.

26. Bergsagel PL. Cyclin D dysregulation: an early and unifying pathogenic event in multiple myeloma. Blood. 2005;106:296-303.

27. Zhang J, Chen F, Li W, Xiong Q, Yang M, Zheng P. 14-3-3Z interacts with Stat 3 and regulates its constitutive activation in multiple myeloma cells. PLoS One. 2012;7:e29554.

28. Hazlehurst LA, Damiano JS, Buyuksal I, Pledger WJ, Dalton WS. Adhesion to fibronectin via integrin $\beta 1 \mathrm{~s}$ regulates p27kip1 levels and contributes to cell adhesion mediated drug resistance (CAM-DR). Oncogene. 2000;19:4319-27. 
29. Lwin T, Hazlehurst LA, Dessureault S, Lai R, Bai W, Sotomayor E. Cell adhesion induces p27Kip1-associated cell-cycle arrest through downregulation of the SCFSkp2 ubiquitin ligase pathway in mantle-cell and other non-Hodgkin B-cell lymphomas. Blood. 2007;110:1631-8.

30. Meads MB, Hazlehurst LA, Dalton WS. The bone marrow microenvironment as a tumor sanctuary and contributor to drug resistance. Clin Cancer Res. 2008;14:2519-26.

31. Lee JW, Juliano R. Mitogenic signal transduction by integrin- and growth factor receptor-mediated pathways. Mol Cells. 2004;17:188.

32. Harburger DS, Calderwood DA. Integrin signalling at a glance. J Cell Sci. 2008;122:159-63.

33. Streuli CH. Integrins and cell-fate determination. J Cell Sci. 2008;122:171-7.

34. Hehlgans S, Haase M, Cordes N. Signalling via integrins: implications for cell survival and anticancer strategies. Biochimica et Biophysica Acta (BBA)Reviews on Cancer. 2007;1775:163-80.

35. Meads MB, Gatenby RA, Dalton WS. Environment-mediated drug resistance: a major contributor to minimal residual disease. Nat Rev Cancer. 2009:9:665-74.

36. Damiano JS, Cress AE, Hazlehurst LA, Shtil AA, Dalton WS. Cell adhesion mediated drug resistance (CAM-DR): role of Integrins and resistance to apoptosis in human myeloma cell lines. Blood. 1999;93:1658.

37. Barda-Saad M, Zhang AS, Zipori D, Rozenszajn LA. Adhesion of Thymocytes to bone marrow stromal cells: regulation by bFGF and IFN- $ү$. Stem Cells. 1997;15(3):229-36.

38. Akeson A, Woods C. A fluorometric assay for the quantitation of cell adherence to endothelial cells. J Immunol Methods. 1993;163:181-5.

39. Wang $Y$, Huang $Y, X u X$, Tang J, Huang $X$. Expression of small glutamine-rich TPR-containing protein a (SGTA) in non-Hodgkin's lymphomas promotes tumor proliferation and reverses cell adhesion-mediated drug resistance (CAM-DR). Leuk Res. 2014 Aug;38(8):955-63.

40. Guan JL. Role of focal adhesion kinase in integrin signaling. Int J Biochem Cell Biol. 1997;29:1085-96.

41. Oellerich T, Oellerich MF, Engelke M, Munch S, Mohr S. beta2 integrinderived signals induce cell survival and proliferation of AML blasts by activating a Syk/STAT signaling axis. Blood. 2013;121:3889-99 S3881-3866.

42. Rajkumar V, Kumar S. Multiple myeloma: diagnosis and treatment. Mayo Clin Proc. 2016:91(1):101-19.

43. Lee S, Cho H, Na G, Yoo MR, Seo S, Hur DY. CD40 stimulation induces vincristine resistance via AKT activation and MRP1 expression in a human multiple myeloma cell line. Immunol LettCopyright (c) 2012 Elsevier B.V. All rights reserved. 2012;144:41-8.

44. Tohnya TM, Figg WD. Immunomodulation of multiple myeloma. Cancer Biol Ther. 2004;3:1060-1.

45. Zheng Y, Yang J, Qian J, Qiu P, Hanabuchi S, Lu Y. PSGL-1/selectin and ICAM-1/CD18 interactions are involved in macrophage-induced drug resistance in myeloma. Leukemia. 2012;27:702-10.

46. Balakumaran A, Robey PG, Fedarko N, Landgren O. Bone marrow microenvironment in myelomagenesis: its potential role in early diagnosis. Expert Rev Mol Diagn. 2010;10:465-80.

47. Yanamandra N. Tipifarnib and Bortezomib are synergistic and overcome cell adhesion-mediated drug resistance in multiple myeloma and acute myeloid leukemia. Clin Cancer Res. 2006;12:591-9.

48. Kurtova A, Balakrishnan K, Chen R, Ding W, Schnabl S, Quiroga M. Diverse marrow stromal cells protect CLL cells from spontaneous and drug-induced apoptosis: development of a reliable and reproducible system to assess stromal cell adhesion-mediated drug resistance. Blood. 2009;114:4441-50.

49. Yingjie L, Jian T, Changhai Y, Jingbo L. Numblike regulates proliferation, apoptosis, and invasion of lung cancer cell. Tumor Biol. 2013;34:2773-80.

50. Tao $T$, Cheng $C$, Ji $Y, X u$ G, Zhang J, Zhang L Numbl inhibits glioma cell migration and invasion by suppressing TRAF5-mediated NF- B activation. Mol Biol Cell. 2012;23:2635-44.

51. Bloma T, Rosellia A, Tannerb M, Nupponena N. Mutation and copy number analysis of LNX1 and Numbl in nervous system tumors. Cancer Genet Cytogenet. 2008;186(2):103-9.

52. Nwaeburu C, Bauer N, Zhao Z, Abukiwan A, Gladkich J, Benner A. Upregulation of microRNA let-7c by quercetin inhibits pancreatic cancer progression by activation of Numbl. Oncotarget. 2016:7(36):58367-80.

53. Liang L, Fan Y, Dandan Z, Meng L, Xiaodong L. Reelin promotes the adhesion and drug resistance of multiple myeloma cells via integrin $\beta 1$ signaling and STAT3. Oncotarget. 2016;7(9):9844-58.

54. Liang L, Xinwei Z, Li C, Quanming A, Jie H. Reelin promotes adhesion of multiple myeloma cells to bone marrow stromal cells via integrin $\beta 1$ signaling. J Cancer. 2017;8(12):2212-22.

\section{Publisher's Note}

Springer Nature remains neutral with regard to jurisdictional claims in published maps and institutional affiliations.

\section{Ready to submit your research? Choose BMC and benefit from:}

- fast, convenient online submission

- thorough peer review by experienced researchers in your field

- rapid publication on acceptance

- support for research data, including large and complex data types

- gold Open Access which fosters wider collaboration and increased citations

- maximum visibility for your research: over $100 \mathrm{M}$ website views per year

At BMC, research is always in progress.

Learn more biomedcentral.com/submissions 